Article

\title{
Transport Accessibility Analysis Using GIS: Assessing Sustainable Transport in London
}

\author{
Alistair C. Ford *, Stuart L. Barr ${ }^{\dagger}$, Richard J. Dawson ${ }^{\dagger}$ and Philip James \\ Centre of Earth Systems Engineering, School of Civil Engineering and Geosciences, \\ Newcastle University, Newcastle upon Tyne, NE1 7RU, UK; \\ E-Mails: stuart.barr@newcastle.ac.uk (S.L.B.); richard.dawson@newcastle.ac.uk (R.J.D.); \\ philip.james@newcastle.ac.uk (P.J.) \\ $\dagger$ These authors contributed equally to this work. \\ * Author to whom correspondence should be addressed; E-Mail: alistair.ford@newcastle.ac.uk; \\ Tel.: +44-191-222-7121.
}

Academic Editors: Mark Zuidgeest and Wolfgang Kainz

Received: 30 October 2014 / Accepted: 9 January 2015 / Published: 20 January 2015

\begin{abstract}
Transport accessibility is an important driver of urban growth and key to the sustainable development of cities. This paper presents a simple GIS-based tool developed to allow the rapid analysis of accessibility by different transport modes. Designed to be flexible and use publicly-available data, this tool (built in ArcGIS) uses generalized cost to measure transport costs across networks including monetary and distance components. The utility of the tool is demonstrated on London, UK, showing the differing patterns of accessibility across the city by different modes. It is shown that these patterns can be examined spatially, by accessibility to particular destinations (e.g., employment locations), or as a global measure across a whole city system. A number of future infrastructure scenarios are tested, examining the potential for increasing the use of low-carbon forms of transport. It is shown that private car journeys are still the least cost mode choice in London, but that infrastructure investments can play a part in reducing the cost of more sustainable transport options.
\end{abstract}

Keywords: network analysis; accessibility; spatial planning; infrastructure investment 


\section{Introduction}

Accessibility to jobs, services or other destinations of interest, has long been recognized as key to the development of sustainable transport, land use and spatial planning strategies [1-5]. Increased emphasis on sustainable urban development has underlined the importance of accessibility for (i) economic development as it enables the movement of people and goods to support the functioning of the economy [6]; (ii) environmental objectives such as reducing greenhouse gas emissions and pollutants that result from different transport modes and how they are used [7]; and (iii) equitable access for all socio-economic groups to core services such as healthcare [8].

Transport systems are key mediators of sustainability in urban areas, as they influence the way people and goods move through a city, and hence the energy (and thus carbon emissions) required to ensure a city functions successfully [9]. Well-designed low-carbon transport systems can encourage transitions from high emission to low emission forms of transport (e.g., from private car to public transport or bicycles). Spatial planning can complement this by encouraging development to occur in areas of good connectivity, ensuring the provision of low-carbon transport options in city plans, or prioritizing mixed-use developments where walking and cycling are more attractive options to travel [9].

Models of transport accessibility, and its interaction with sustainability, have been developed over many years. Hansen [10] showed a strong correlation between the accessibility of an area within a city and its ability to attract new urban development or investment. This concept was extended by Lowry [11] as a land-use transport model where the spatial separation of (or the ease of travel between) population and employment is a key determinant of land-use (see Levinson [12] for a more recent application of such a model). These models used measurements of time or distance in their assessment of sustainability and thus the carbon emissions of a journey were not considered. Further developments in urban land-use transport models [4,13-18] use a range of approaches, often with more sophisticated representations of urban processes, but central to these models is the characterization of transport accessibility [19]. Consequently, whilst accessibility calculations have often been wrapped within land-use transport models, the importance of understanding accessibility in its own right has more recently led to the development of a number of specific accessibility tools (see [5] for a review of such tools employed in Europe), some of which are standalone tools whereas others have been developed in a GIS environment.

Many of these tools have been developed for specific cities (e.g., CAPITAL is a London-specific tool [20]) or their access is restricted to specific audiences (e.g., the UK Department for Transport Accession GIS tool [21]). The data and computational overheads with these, and many other models, can be a barrier to adoption by non-specialist decision-makers (see Te Brömmelstroet et al. [22] for a discussion on usability), reduce their utility for rapidly exploring a wide range of options and policies, and limit the feasibility of their incorporation into a broader assessment of non-transport urban sustainability issues (e.g., which might consider a diverse range of issues such as flood risk and energy consumption for a number of different scenarios).

GIS platforms have, for some time, supported transport planning by analysis of spatial patterns, such as calculating the shortest path between two points on a network [23]. Tools commonly included in commercial GIS software offer interactive and rapid calculations on simple networks but are insufficient for a rich understanding of urban accessibility (e.g., inclusion of scheduling information or the monetary 
costs of journeys). Improvements to these basic GIS functions have been presented in recent years; Liu and Zhu [2] developed an accessibility toolkit for ArcView GIS, measuring accessibility by different modes and to various destinations, Lei and Church [24] included walking times and transit frequencies in their assessment of accessibility, Benenson et al. [25] introduce an ArcGIS-based toolkit to calculate service areas and travel times including transfers and timetable information for public transport, and Mavoa et al. [26] calculated different accessibility scored by public transport for 17 different destination types. In addition, more advanced analysis of accessibility using graph-theoretical approaches have been developed [27,28].

Building on these advances, this paper introduces a model designed to exploit the capabilities of GIS in order to support strategic planning for sustainable urban transport by enabling rapid appraisal of city-wide transport options, here using generalized cost of travel as a comparative metric. This methodology addresses some of the limitations of standard desktop GIS packages to provide a more sophisticated understanding of accessibility (e.g., following some of the methodologies highlighted above to include such improvements as generalized cost of travel and access times to services as opposed to standard shortest pathway analysis), whilst taking advantage of the strengths of GIS (over standalone tools) as an interactive data manipulation, spatial analysis, network analysis and visualization tool. In particular, a GIS framework enables non-specialists and decision-makers to interact directly with the model and the input data in order to rapidly test scenarios on their desktop and to explore the results and data which show the accessibility landscape for a city in a familiar environment. Such results can be further examined in the GIS software using in-built geo-statistical analysis tools.

An additional advantage is that GIS enables the combination of other model outputs and spatial datasets of interest in order to examine the transport appraisal results in context, enabling for example direct comparison between low-carbon and carbon-intensive forms of transport, thus giving insights into areas where sustainable transport investment is needed. Moreover, this has enabled the rapid accessibility analysis tool to be widely employed within an "Urban Integrated Assessment Facility" (described in Hall et al. [29] and Walsh et al. [30]) which is used for the analysis of climate change policy in cities. In this paper, we analyze the potential benefits of a number of infrastructure investment scenarios for Greater London in the UK, including future investment scenarios proposed by Transport for London, which demonstrate how London might increase urban accessibility with more sustainable modes of transport.

\section{Measuring Transport Costs and Accessibility}

There are many definitions of accessibility in the literature; however, a general definition by Wachs and Kumagi [31] is that accessibility is the ease (or difficulty) that opportunities (e.g., employment) or services can be reached from a location. Accessibility captures the effort required to overcome the spatial separation of two locations, and usually reflects the utility (e.g., travelling from home to a job) associated with travelling between these locations [5,32,33]. Geurs and Van Wee [3] provide a full review of accessibility measures, but the most generalized formulation of the accessibility, $A$, of location, $i$, is from Koenig [34]: 


$$
A_{i}=\sum_{j} O_{j} f\left(C_{i j}\right)
$$

where $O_{j}$ are the opportunities (utility or activity) to be gained from travelling to location $j, C_{i j}$ is the distance, time, or cost of travelling from $i$ to $j$, and $f\left(C_{i j}\right)$ is a function which ensures that the accessibility increases as the cost of travel between two locations decreases [35]. Thus, fundamental to understanding accessibility is the cost of travel between an origin and a destination. This cost, or impedance, can be measured in a number of ways. The simplest measure is the Euclidian distance between two points which was typically used in earlier analyses [10,11]. Availability of transport network information has enabled more realistic network path analysis of distance; the shorter the distance, the higher the accessibility [36]. However, this does not take into account the physical network structure of transport modes or their different financial overheads, speeds, frequencies, levels of effort required in their use, interchange times and capacities [37,38]. Therefore, in this work the cost of travel is expressed as a generalized cost, taking into account both time and monetary components of any journey along the transport network in one unified value $[39,40]$. This makes the assumption that the cost of travel between an origin and destination can be generally expressed in the form:

$$
G=g\left(C_{1}+C_{2}+\cdots+C_{n}\right)
$$

where generalized cost $G$ is a function of a set of cost components of a journey, $C_{1}$ to $C_{n}$, which may be expressed in terms of time or money [39]. These cost components may be physically measurable (such as the cost of a ticket or the time taken to walk to a railway station) or more subjective (such as a user's preference for a particular type of transport or the relative comfort of a mode). The use of generalized cost provides a simple unit of comparison for the cost of journeys which includes as many of the influences which affect the choice of transport as possible. The UK Department for Transport's "Transport Analysis Guidance" [41] defines generalized cost as "the sum of both the time and money cost" for a journey, or:

$$
C=a D+b T
$$

where $D$ is the distance $(\mathrm{km})$ between origin and destination, $T$ is the time in hours taken to complete the journey, $a$ is a distance coefficient based on vehicle operating costs per $\mathrm{km}$, and $b$ is the value of time coefficient. Costs are incurred differently by private, $C_{P V T}$, public, $C_{P U B}$, or cycling, $C_{C Y C}$, transport, expressed in units of time by WEBTAG [41] as follows:

$$
\begin{gathered}
C_{P V T}=\left(V_{w k} * A\right)+T+D * \frac{V O C}{o c C * V O T}+\frac{P C}{o c C * V O T} \\
C_{P U B}=\left(V_{w k} * A\right)+\left(V_{w t} * W\right)+T+\frac{F}{V O T}+I \\
C_{C Y C}=T+T\left(V_{\text {Topo }}+V_{\text {Safe }}\right)
\end{gathered}
$$

where $A$ is the access time to the network (walk time to car, bus stop, light rail station or railway station); $V_{w k}$ is the disincentive weight for walking; $T$ is the journey time of transport; $V O C$ is the vehicle operating cost per $\mathrm{km} ; D$ is the distance in $\mathrm{km} ; P C$ are parking and other costs; occ is the number of vehicle occupants; $V_{w t}$ is the disincentive weight for waiting; $W$ is the total waiting time for the journey; $I$ is the interchange penalty (if applicable); $F$ is the fare 
paid for a journey; VOT is the value of time coefficient; $V_{\text {Topo }}$ is the disincentive weight for cycling up slopes; and $V_{\text {Safe }}$ is the disincentive weight to represent safety concerns for cyclists on busy roads. Further explanation, and the values used for the modeling study presented in Section 4, are given in Section 3.

It can be seen from Equations (4a)-(4c) that the in-vehicle time of any given journey is thus only one of several factors that contribute to the overall cost of travel [2]. Furthermore, time for waiting or walking to access a particular mode of transport captures the disincentive of certain options, and is sometimes referred to as the system accessibility [21]. VOT defines the value that the average person places on a unit of their time, or their willingness to pay for a service, in monetary terms [42]. The value of time varies for different socio-economic groups and other factors such as the urgency of a given journey and differs depending on whether the time is working or non-working time (which is of concern here), with higher values for the former. However, it enables direct comparison and combination of both the monetary and time components of journey cost $[42,43]$.

A transformative shift in improving the sustainability of transport is switching journeys from carbon-intensive modes (such as private cars) to low-carbon or zero-carbon modes (i.e., walking and cycling) [9]. As such, it was considered important to include a representation of the cycling mode in this generalized cost framework. Cycling routes can be considered to predominately follow the road network in most cities, with the addition of a limited number of paths and routes exclusively for cycle use. The generalized cost calculation for a cycle journey is thus a simplified version of the method for private vehicles (Equation (4a)) since there are fewer monetary costs associated with trips. There are, however, additional factors to consider in the cost of cycling. Hopkinson and Wardman [44] highlighted that the gradient of routes along which cyclists may travel is one of the factors influencing cyclists' route choices, whilst Noland and Kunreuther [45] indicated that the perception of risk (i.e., the safety) of a journey is an important consideration. Rodriguez and Joo [46] also allude to this in their study, showing that the physical environment (e.g., the provision of pedestrian or cycling infrastructure) has an effect on the perceived cost of non-motorized journeys. These factors are therefore included as additional weights in the computation generalized costs for cycling journeys.

\section{Implementation of GIS-Based Model}

To develop a tool that is generic and transferable, able to accept standard GIS input in the form of spatial data, at any given scale, and perform the generalized cost computation to produce a set of accessibility measures, an add-in was developed in VBA for ESRI's ArcGISC. The utility of this add-in was demonstrated using a case study in the Greater London Authority (GLA) area in the UK (see Section 4 for details description of the implementation and results of this case study). Figure 1 shows the computational process for calculating generalized cost matrices for a given mode. 


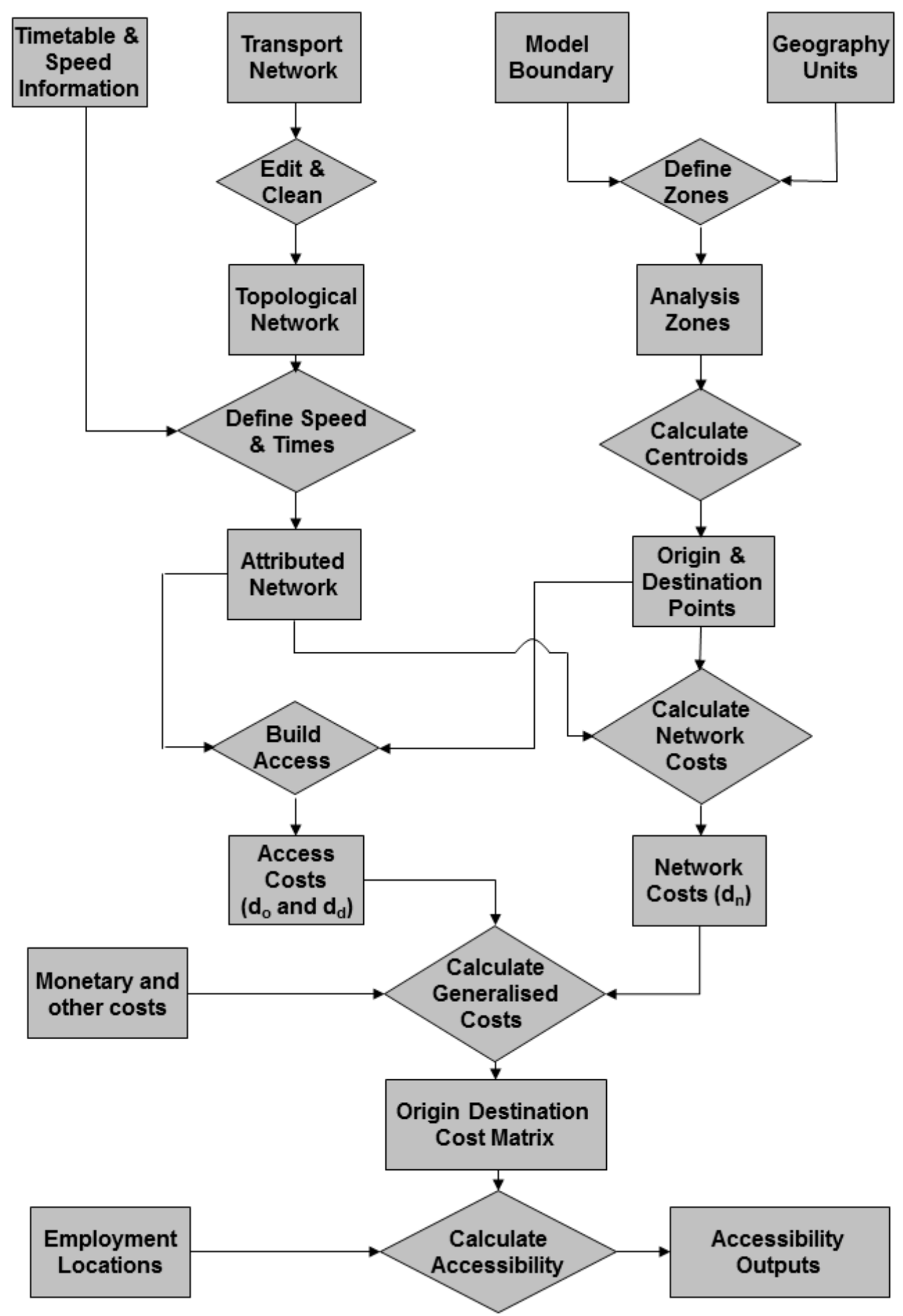

Figure 1. Computation framework for matrices of generalized cost, and thus accessibility measures. Employment locations could be replaced by other information to calculate accessibility to other facilities.

The generalized cost model (Figure 1) was implemented as follows using values in Table 1 for the different terms of Equations (4a)-(4c): 
1. First, the spatial geography of the model is defined in terms of zonal geography and the spatial boundary of analysis (for example for the London case study presented below, these are UK Census Area Statistics Wards, i.e., zones on which 2001 UK census outputs are reported).

2. Build $M$ transport networks:

a. Analyze, and clean if necessary, the data to ensure the correct topological structure for creation of a spatial network model.

b. Build spatial networks within GIS software.

c. Calculate the length of each network link from geometry.

d. Multiply each network link length by the relevant travel speed to obtain the travel time for each link.

3. For $N$ units of spatial geography, create an $N \times N$ matrix of generalized costs for each of the $M$ transport modes (similar to the approach outlined by Benenson et al. [24]):

a. Calculate the location of the centroid and use it to define the Origin, and Destination of zone $i$.

b. Calculate access distance, $d_{o}$, and associated travel time from centroid to nearest network access location (private and cycling modes), or boarding point (public transport modes) (Figure 2)

c. Calculate shortest (network) path, $d_{n}$, between origin and destination centroids using Dijkstra's algorithm [47] (Figure 2). Shortest routes based on time, rather than distance, are computed in order to take into account speeds of travel. This is facilitated by ESRI's Network Analyst extension [48].

d. Calculate access distance, $d_{d}$, and associated travel time from destination station or stop (public transport) or road access location (private and cycling modes) (alighting point) to the centroid of the destination zone (Figure 2).

e. Eliminate nonsensical journeys (e.g., where nearest station is shared between the origin and destination) and return a no-data value.

f. Add on other costs, including non-monetary and monetary components in Equations (4a)-(4c) such as fuel or perception weights, converted to time.

g. Sum all journey components to calculate the generalized cost of travel, $C_{i j}$, between two zones.

h. For situations where $i=j$ and the preceding steps calculate $C_{i j}=0$ then assume that $C_{i j}=\frac{2}{3} \min \left(C_{i j(i \neq j)}\right)$ in line with the approach used by Feldman et al. [49].

4. Use computed generalized costs to determine accessibility to destinations of interest (e.g., employment locations) and determine the proportion of employment which is accessible by a given mode in a given cost of travel. 


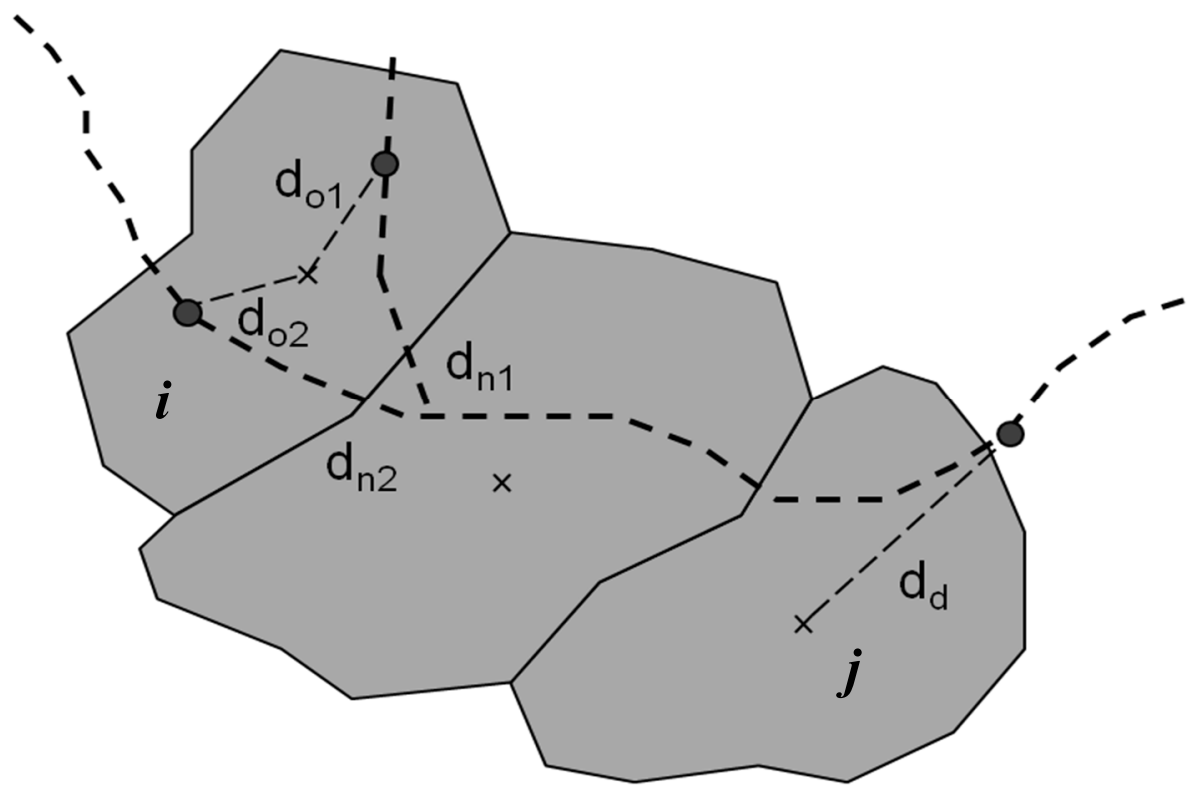

Figure 2. Schematic depiction of journey from origin $i$ to destination $j$.

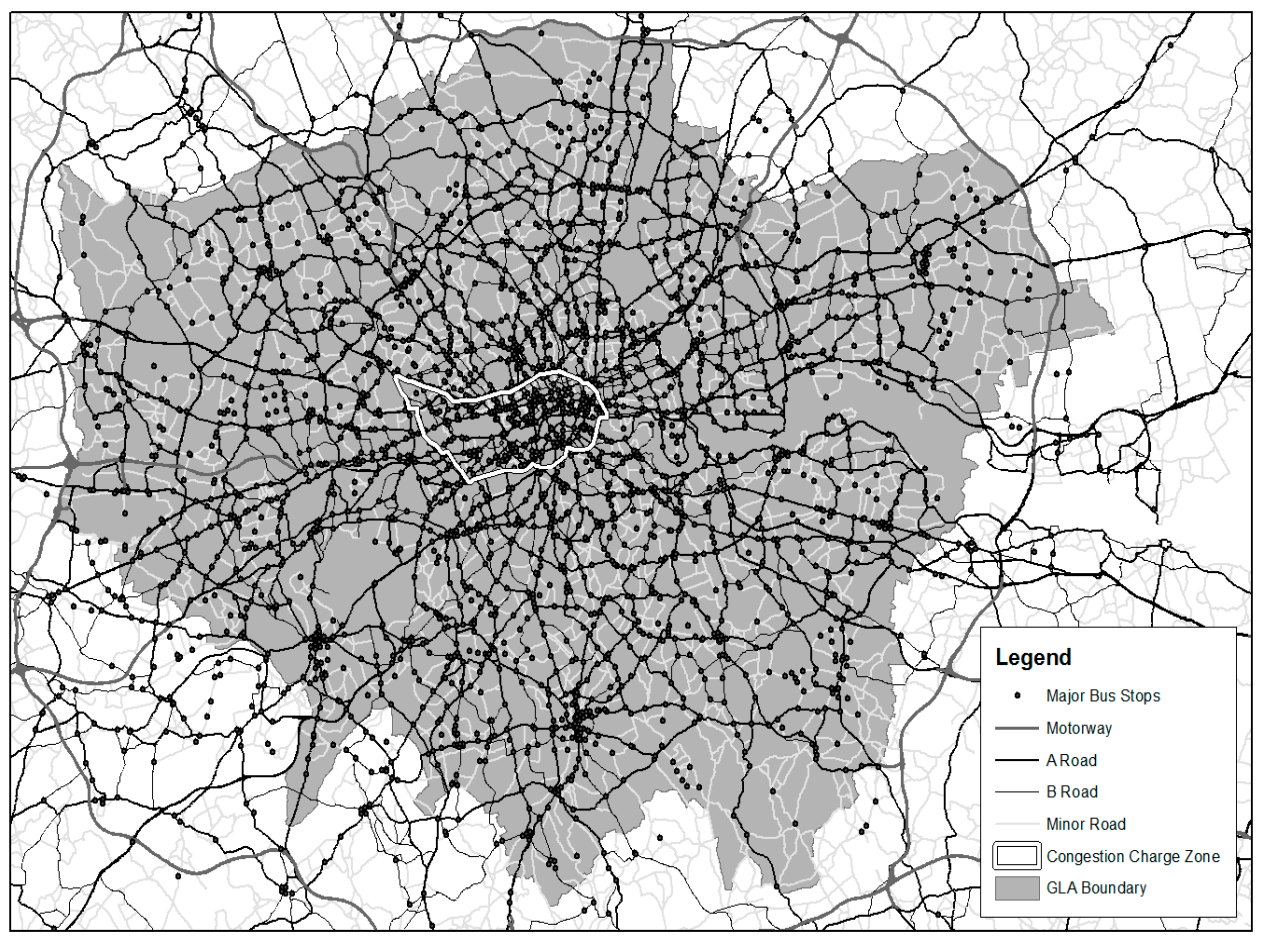

Figure 3. Baseline road network, and bus stops, in the Greater London area. The Congestion Charge Zone is also depicted.

Figure 3 shows the geographic extent of the road-based (private vehicle travel and Bus) networks as implemented in the London case study, highlighting the size of these networks (in the order of 65,000 links). Figure 4 shows a sample of the OpenStreetMap cycle network constructed for this study, demonstrating the density of the network in the urban area and the number of possible travel routes to be assessed. The calculation of network distance, $d_{n}$, used the above algorithm for all modes, with appropriate values (i.e., speeds) from Table 2 to establish a UK context. However the calculation of 
network access distance $d_{o}$ and $d_{d}$ for public and private networks differs as public transport networks must be accessed from stops where passengers can board and alight from services, with these stops being connected by routes. Unlike the public transport modes, the road and cycle networks can be accessed at any point along a link. Therefore $d_{o}$ and $d_{d}$ are calculated as the Euclidean distance from the centroid to the nearest stop or station for public transport and nearest road link for private transport. This is undertaken using a spatial join in the GIS software.

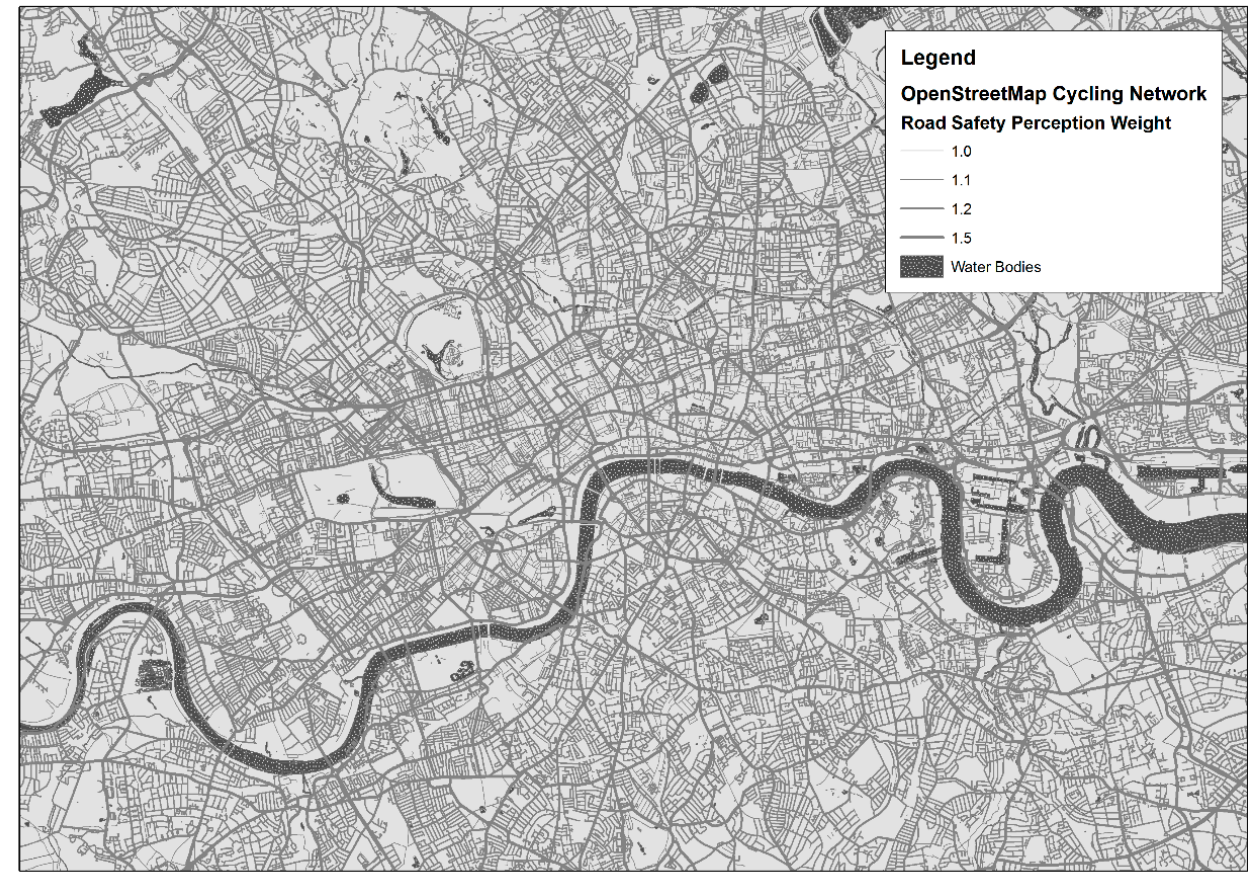

(C) OpenStreetMap contributors

Figure 4. The OpenStreetMap-based cycling network data for London, showing weights based on the class of road to represent perceptions of safety (see Table 2 for an explanation of the values).

It is possible that origin or destination zones may contain more than one station or stop (for example, in London $10 \%$ of zones have more than one heavy rail station and over half have no station at all, whilst the numbers are one in three and one in five for light rail). If there are fewer than two stations in the zone the nearest is used, whether it falls within the zone or not (Figure 2), to define $d_{o}$ and $d_{d}$. If both the origin and destination zones have fewer than two stations then there is only one possible route between the zones. However, if either the origin or destination contain more than one station, then for a total of $S_{i j}$ stations (e.g., maximum Sij for light rail in the London is 16) the average distance over all route combinations is calculated:

$$
D_{i j}=\sum_{k=1}^{S_{i j}} \frac{d_{o}^{k}+d_{n}^{k}+d_{d}^{k}}{S_{i j}}
$$

A number of additional assumptions have been made to ensure that the generalized cost model is flexible, can be constructed on simple, publicly-available data, and runs quickly. For public transport networks (bus, heavy rail, and light rail), it is assumed that all portions of the heavy and light rail 
networks are passenger-carrying (although pre-processing can be undertaken to only include rail lines with stations). There is no limit imposed on access times to the transport networks (e.g., walking times to stations); a maximum walking time to a public transport stop or station could be implemented to reflect the low likelihood of someone walking further without using an alternative mode of transport. For example, NHTSA [50] show that many people will only walk 0.5 miles. To enable direct comparison between modes, for journeys between all zones, this was not implemented here. However, the disincentive of long walking times is still captured in the generalized cost calculation. Interchanges within the same transport mode are calculated by adding walking costs between stations to the cost of travel.

Table 1. Infrastructure improvements implemented in Baseline, Low and High investment scenarios (based on Transport 2025 report [51]).

\begin{tabular}{|c|c|c|c|c|}
\hline T2025 Scenario & Road & Bus & Rail & Light Rail \\
\hline Baseline & & & $\begin{array}{l}\text { Crossrail } \\
\text { High Speed } 1 \\
\text { Heathrow Express } \\
\text { to Terminal } 5\end{array}$ & $\begin{array}{l}\text { Heathrow Terminal } 5 \\
\text { extension }\end{array}$ \\
\hline Low & $\begin{array}{l}\text { Thames } \\
\text { Gateway Bridge }\end{array}$ & $\begin{array}{l}20 \% \text { increase } \\
\text { in bus supply } \\
\text { (and thus } \\
\text { frequency) }\end{array}$ & $\begin{array}{l}\text { Reduce journey } \\
\text { time by } 4.5 \%\end{array}$ & $\begin{array}{l}\text { DLR extensions, } \\
\text { Greenwich and East } \\
\text { London transit systems }\end{array}$ \\
\hline High & $\begin{array}{l}\text { Silvertown Link } \\
\text { Bridge } \\
\text { National Road } \\
\text { User-charging } \\
\text { scheme }\end{array}$ & $\begin{array}{l}40 \% \text { increase } \\
\text { in bus supply. }\end{array}$ & $\begin{array}{l}\text { Crossrail 2, East } \\
\text { London line } \\
\text { extension } \\
\text { (Overground). }\end{array}$ & $\begin{array}{l}\text { Tramlink extensions, } \\
\text { DLR extension to } \\
\text { Dagenham Dock }\end{array}$ \\
\hline
\end{tabular}

In the case of private transport networks (road and cycling) most cost elements are included on the links themselves, since non-time components are often accrued in a distance-based manner. Thus, for example, the impact of topography on cycling is incurred on a link-by-link basis. Congestion charging or other road user charging schemes must be included as on-link costs (i.e., by means of increasing travel times along a link through Value of Time conversion). See Section 4 for a discussion of the London Congestion Charge and its implications.

All network elements (e.g., roads, cycle routes, or railway lines) are bi-directional. Some road network data (e.g., Ordnance Survey ITN in the UK) includes driving direction which means that it is possible to trace routes through one-way systems, however for large analyses (e.g., the $1500 \mathrm{~km}^{2}$ of London) such local-scale factors are not significant for global accessibility. On the same basis, the effect of gradient is assumed to impact on cycle journeys equally in both directions. 
Table 2. Summary of generalized cost components used in this case study of the GIS accessibility model.

\begin{tabular}{|c|c|c|}
\hline Parameter & Description & Value Used in Analysis \\
\hline$A$ & $\begin{array}{l}\text { Time take to access a given transport network mode from } \\
\text { a place of residence. This uses } d_{o} \text { and } d_{d} \text { which are the } \\
\text { distance from the transport mode to the zone centroid } \\
\text { (Figure 2). }\end{array}$ & $\begin{array}{l}\text { Private transport modes: } 3 \text { min - the maximum access distance in Greater London is } 800 \mathrm{~m} \text { (in the } \\
\text { Hillingdon ward in western Outer London), with the mean distance being } 130 \mathrm{~m} \text {. } \\
\text { Public transport modes: Distance from zone centroid to station, with a walking speed of } 6 \mathrm{~km} / \mathrm{h}\end{array}$ \\
\hline$V_{w k}$ & $\begin{array}{l}\text { Weight applied to the walking component of a journey to } \\
\text { reflect the increased perceived cost of walking compared } \\
\text { to other transport modes (applied to } d_{o} \text { and } d_{d} \text { ). }\end{array}$ & 1.6 from WEBTAG [41] \\
\hline$T$ & $\begin{array}{l}\text { The in-vehicle travel time is computed by multiplying the } \\
\text { network distance by an average speed. This is the time } \\
\text { taken to travel distance } d_{n} \text {. }\end{array}$ & $\begin{array}{l}\text { Computed from network analysis described in Section } 2 \text {. } \\
\text { Car: defined by } 2006 \text { London Travel Report Table 3.2.1, which gives the average journey speed } \\
\text { for three traffic zones; central, inner and outer London [52]. } \\
\text { Heavy rail: } 40 \mathrm{~km} / \mathrm{h} \\
\text { Light rail: } 30 \mathrm{~km} / \mathrm{h} \\
\text { Bus: times supplied in network data }\end{array}$ \\
\hline$W$ & $\begin{array}{l}\text { Waiting time is calculated as half the average morning } \\
\text { peak service frequency for public transport modes. }\end{array}$ & $\begin{array}{l}\text { Rail: } 7.5 \mathrm{~min} \\
\text { Light rail: } 3 \mathrm{~min} \\
\text { Bus: } 3 \mathrm{~min}\end{array}$ \\
\hline$V_{w t}$ & $\begin{array}{l}\text { Weight applied to any waiting time, reflecting the } \\
\text { perceived cost of waiting compared to travelling, and a } \\
\text { dislike of waiting for infrequent services. }\end{array}$ & 2.6 from WEBTAG [41] \\
\hline$D$ & $\begin{array}{l}\text { Distance travelled }(\mathrm{km}) \text { traversing the least cost path from } \\
\text { origin to destination, and is equivalent to } d_{n} \text { (Figure } 2 \text { ). }\end{array}$ & Computed from network analysis. \\
\hline$V O C$ & $\begin{array}{l}\text { Vehicle Operating Cost is the sum of both fuel, } V O C_{f} \text {, and } \\
\text { non-fuel, } V O C_{n f} \text {, costs (which capture maintenance and } \\
\text { depreciation costs). }\end{array}$ & $\begin{array}{l}\text { Fuel costs, } \\
V O C_{f}=\mathbf{F}_{m} \mathbf{F}_{\boldsymbol{p}} \\
\text { where } \mathbf{F}_{\boldsymbol{m}} \text { is a vector of the vehicle mix and their fuel efficiency and } \mathbf{F} \boldsymbol{p} \text { is a vector of fuel prices. } \\
\text { Non-fuel operating costs can be computed by the following: } \\
V O C_{n f}=a 1+\frac{b 1}{V} \\
\text { where } V=\text { average velocity in } \mathrm{km} / \mathrm{h} ; a 1=4.069 ; b 1=111.391\end{array}$ \\
\hline
\end{tabular}


Table 2. Cont.

\begin{tabular}{|c|c|c|}
\hline Parameter & Description & Value Used in Analysis \\
\hline VOT & Value of Time. & 1 hour $=£ 5.04$ from WEBTAG $[41]$ \\
\hline$o c c$ & Average number of occupants in a private vehicle. & 1.16 people per vehicle $[41]$ \\
\hline$P C$ & $\begin{array}{l}\text { Other private transport costs. Information on parking costs } \\
\text { and policies was incomplete for London so have not been } \\
\text { included in this analysis. However, the London Congestion } \\
\text { Charge, levied on vehicles entering the center of the city, } \\
\text { has been included. }\end{array}$ & $\begin{array}{l}\text { Congestion Charge of } £ 8 \text { ( } 2008 \text { charge) levied on each journey into the charging zone. } 90 \% \\
\text { discount for residents of the zone travelling out for work [53]. }\end{array}$ \\
\hline$F$ & $\begin{array}{l}\text { The fare paid for a given origin-destination route varies } \\
\text { according to the time of day and whether the individual has } \\
\text { a season ticket, travel card, or uses an "Oyster Card". An } \\
\text { average rail and light rail cost is reported in the London } \\
\text { Travel Report (TfL, 2006). Flat bus fares } £ 2 \text {, or } £ 1 \text { with } \\
\text { an "Oyster Card". However, } 85 \% \text { of journeys (TfL, 2007) } \\
\text { use an Oyster Card so this was used for all journeys in } \\
\text { this analysis. }\end{array}$ & $\begin{array}{l}\text { Heavy and light rail: } £ 0.18 / \mathrm{km} \\
\text { Bus: } £ 1 \text { flat fare }\end{array}$ \\
\hline$V_{\text {Topo }}$ & $\begin{array}{l}\text { It is assumed that cycling journeys incur a lower cost on } \\
\text { flatter terrain than on more undulating terrain. In this } \\
\text { paper, a modified version of Naismith's Rule is used, } \\
\text { where each unit of vertical change adds } 1 / 8^{\text {th }} \text { of a unit of } \\
\text { horizontal distance to the journey. }\end{array}$ & $\begin{array}{l}1 / 8 *\left(Z_{\max }-Z_{\min }\right) \text { for a given road link, where } Z \max \text { and } Z \min \text { are the maximum and minimum } \\
\text { elevations at either end of the link. }\end{array}$ \\
\hline$V_{\text {Safe }}$ & $\begin{array}{l}\text { One of the largest disincentives to cycling in urban areas } \\
\text { is the issue of safety on the road network (especially in } \\
\text { London, where cycling infrastructure is patchy and a } \\
\text { number of cyclists are killed every year). A weight is } \\
\text { therefore applied based on the class of road being } \\
\text { traversed. These are assumed weights but can be simply } \\
\text { altered to reflect further research on perceptions of risk. }\end{array}$ & $\begin{array}{l}\text { A-Roads, B-Roads: } 1.5 \text { times base travel time } \\
\text { Minor roads: } 1.2 \\
\text { Residential streets and pedestrian paths: } 1.1 \\
\text { Cycle lanes: } 1 \\
\text { Adapted from the methodology employed in the CycleStreet route planner [54] }\end{array}$ \\
\hline
\end{tabular}




\section{Results and Discussion of London Accessibility Study}

The above computation framework was used to compute origin-destination matrices of generalized cost of travel under a number of current and future transport infrastructure scenarios for an application in the Greater London Authority (GLA) area in the UK. The future scenarios which were examined are based on the Transport for London "Transport 2025" study [51] options for future infrastructure developments. This study sets out a number of strategies to achieve the aim of ensuring London becomes a "sustainable world city", including supporting sustainable economic development, improving social inclusion, and tackling climate change and enhancing the environment [51]. Part of this strategy is a desire to improve the use of low-carbon transport modes through new infrastructure provision and encouraging behavioral change.

These scenarios were generated in the form of spatial network representations and parameterizations within the methodology outlined in the previous section, thus allowing the testing of their impacts on accessibility in the Greater London area. To facilitate model set-up and to demonstrate ease of use, accessibility is characterized using nationally-available data-sets in the UK. Datasets of this type are often available in other countries and increasingly collected according to the same data standards, which limits the time required for data preparation. Improved accessibility to areas of high economic activity by lower-carbon modes of transport can therefore be provided as evidence that such infrastructure plans are meeting the city's sustainability goals. Table 1 summarizes the future infrastructure scenarios examined in this study. Specific improvements for cycling network infrastructure were difficult to obtain (none are mentioned in the Transport 2025 report beyond the development on on-road cycle lanes) so are not included in this table.

The model boundary for this study was defined as the edge of the Greater London Authority for reasons of political jurisdiction and data access, as this area is the defined administrative boundary that is most pertinent to decision-makers. Transport network representations were also restricted to this boundary, although this introduced a limitation in that some possible radial routes outside the administrative boundary of the city are not considered in the generalized cost calculation. Only journeys internal to this study area were considered, since the consideration of this study was accessibility between locations within the GLA region. Zonal units for origins and destinations in this study were the UK Census Area Statistics Wards (i.e., zones on which 2001 UK census outputs are reported) of which there are 633 within the GLA area ranging in population from 106 to 17,000 , and in size from $0.13 \mathrm{~km}^{2}$ to $29 \mathrm{~km}^{2}$ (mean size of $2.5 \mathrm{~km}^{2}$ ) of UK Census Area Statistics Wards were used as they allowed a direct comparison between the computed transport accessibility measures and the socio-economic variables of the zones.

One feature of London's transport policy of particular interest is the central London "Congestion Charge zone", which levies a fee on vehicles entering between 07:00 to 18:00 (see Table 2). Residents commencing their journeys within this zone receive a $90 \%$ discount. As mentioned above, these charges were added to the spatial road network representation directly to enable it to be factored into the calculation of the least cost network route, $d_{n}$ in the generalized cost computation. This ensures that journeys will be routed around the congestion zone if the overall cost is lower than traversing the center of London. Table 2 lists the complete parameterisation and data inputs used in the London case study. 


\subsection{Testing New Infrastructure Investment}

A key purpose of this GIS tool is to rapidly assess the effects of new infrastructure developments on accessibility patterns. Here, some options from the aforementioned T2025 scenarios of infrastructure development ([51], summarized in Table 1) are considered individually. The changes in generalized costs resulting from such developments are first shown spatially in this section, then their impact on accessibility to employment and wider sustainability impact discussed in later sections.

Crossrail is a program to construct a new East-West Heavy Rail link in London connecting Paddington to the Liverpool Street and Canary Wharf areas. This includes a new section of railway line in a tunnel beneath central London and improvements to existing lines either end of the tunnel to allow higher speeds and greater capacity [55]. These improvements were included in the network model by means of new links and stations to reflect the new tunnel route and increased speeds on the existing lines to reflect greater frequency and shorter travel times. The fare was assumed to be consistent with other rail travel.

The difference between the generalized cost of travel from Heathrow Villages to other census wards pre- and post-Crossrail is shown in Figure 5. This reveals a mean generalized cost benefit of 12 min to census wards across London, but the zones to the immediate east of the Crossrail tunnel show a benefit of up to an hour. Such patterns of improvement demonstrate the increased accessibility to areas to the east of central London (such as Canary Wharf and the former docklands regions) where there are a high number of jobs (around 132,000 people employed in 15 CAS wards in 2005) and a large amount of development. This demonstrates that the construction of Crossrail may improve the use of sustainable modes of transport to such areas.

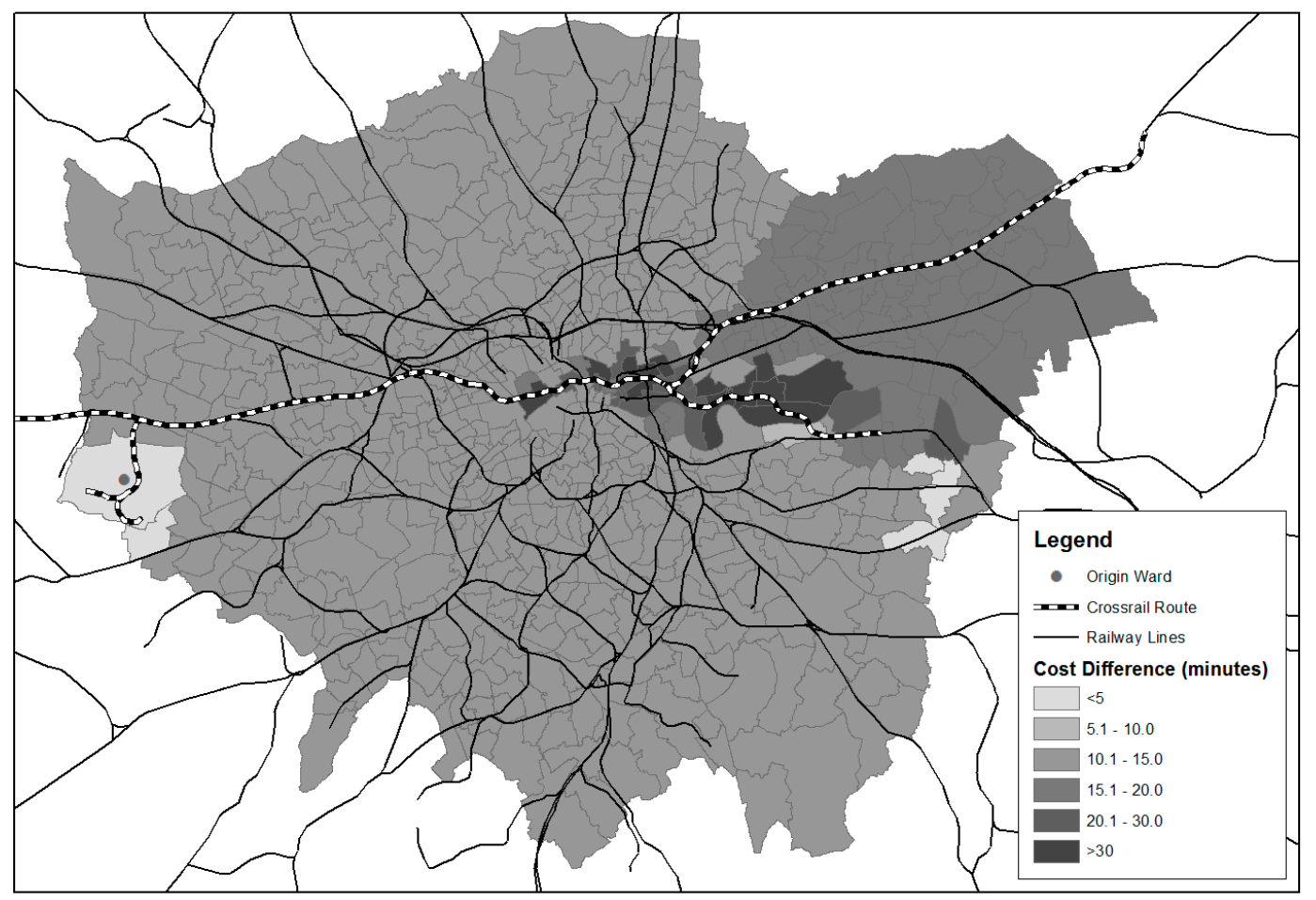

Figure 5. A comparison of pre- and post-Crossrail generalized costs from the Heathrow Villages ward to other wards in the GLA area. 
Another proposed infrastructure upgrade is the Thames Gateway Bridge, a new road crossing of the River Thames to the east of the City of London. Figure 6 shows the generalized cost benefit by road from the Plumstead ward. It can be seen that most reductions in generalized cost are in cross-river journeys (as would intuitively be expected) although there are also reductions in journey times to more distant wards in north London. Wards immediately north of the river experience the greatest reduction in cost (up to $30 \mathrm{~min}$ ) as it is possible to cross the River Thames at a much closer point than in the baseline network. However, if a proposed $£ 2$ bridge crossing toll is added, then the generalized cost benefit is negated (since $£ 2$ equates to approximately $24 \mathrm{~min}$ of journey time). Whilst some of these reductions are modest, they highlight the wider spatial effects of localized infrastructure improvement. Both projects provide regional benefits, but the structure of the rail network leads to the greatest benefits from Crossrail being focused in fewer wards than for the bridge. This highlights the need to examine the system improvements at city-scale from improvements which could be considered local.

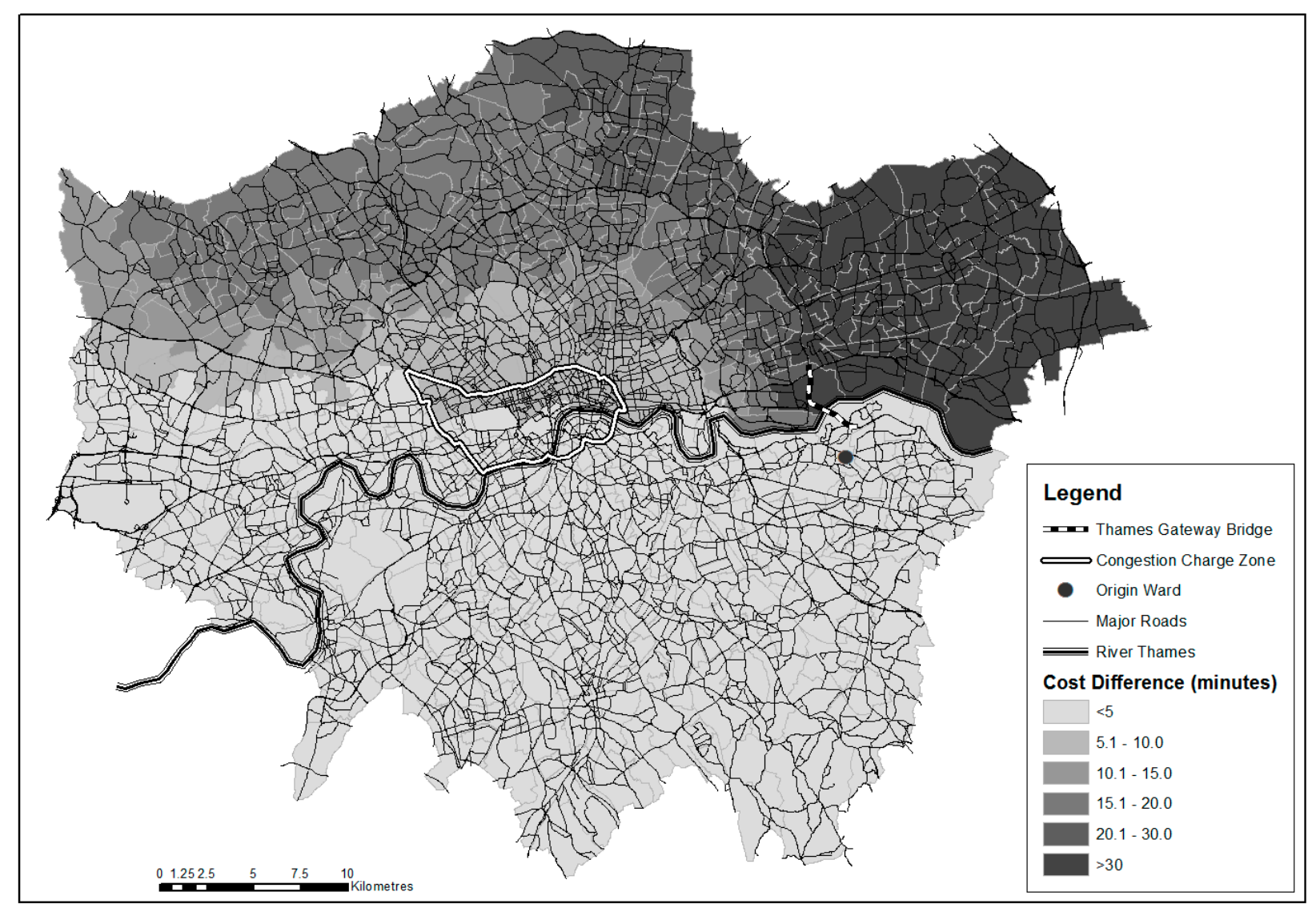

Figure 6. Changes in generalized cost, measured from the Plumstead ward, from the construction of the Thames Gateway Bridge in east London.

Whilst there are no specific infrastructure investments for cycling outlined in the Transport 2025 report, there is mention of an aspiration to further develop the London Cycle Network Plus (LCN+), a network of up to $900 \mathrm{~km}$ cycle routes. Much of this network is in the form of on-road cycle lanes but, more recently, Cycle Superhighway routes have been proposed. One of these is the $10 \mathrm{~km}$-long East-West Cycle Superhighway, running along the River Thames through central London on a dedicated piece of infrastructure [56]. This is a relatively small piece of infrastructure, but its impact on cycling 
journey costs through this part of central London was analyzed to examine the local improvements which could be seen from constructing such dedicated infrastructure.

Figure 7 shows the reduction in travel cost by the cycling mode between the Plaistow South ward in east London and the other wards in the local area. Improvements of up to 14 min of generalized cost can be observed, due to a combination of shortened journey times (due to higher speeds on dedicated cycling infrastructure) and a reduced perception of risk from the provision of segregated cycle lanes. Such improvements increase the competitiveness of cycling journey costs in comparison with other modes (for example, cycle costs from Plaistow South to Golborne in west London are 91 min after the construction of the East-West Cycle Superhighway. This compares favorably with the travel cost by private car (162 min, since this journey travels through the Congestion Charge zone), light rail (105 $\mathrm{min}$ ), and bus (also $105 \mathrm{~min}$ ). If other such infrastructure was provided in a wider context across London, the reductions in travel cost could be large enough to ensure that zero-carbon modes of transport are a competitive alternative for short distance journeys.

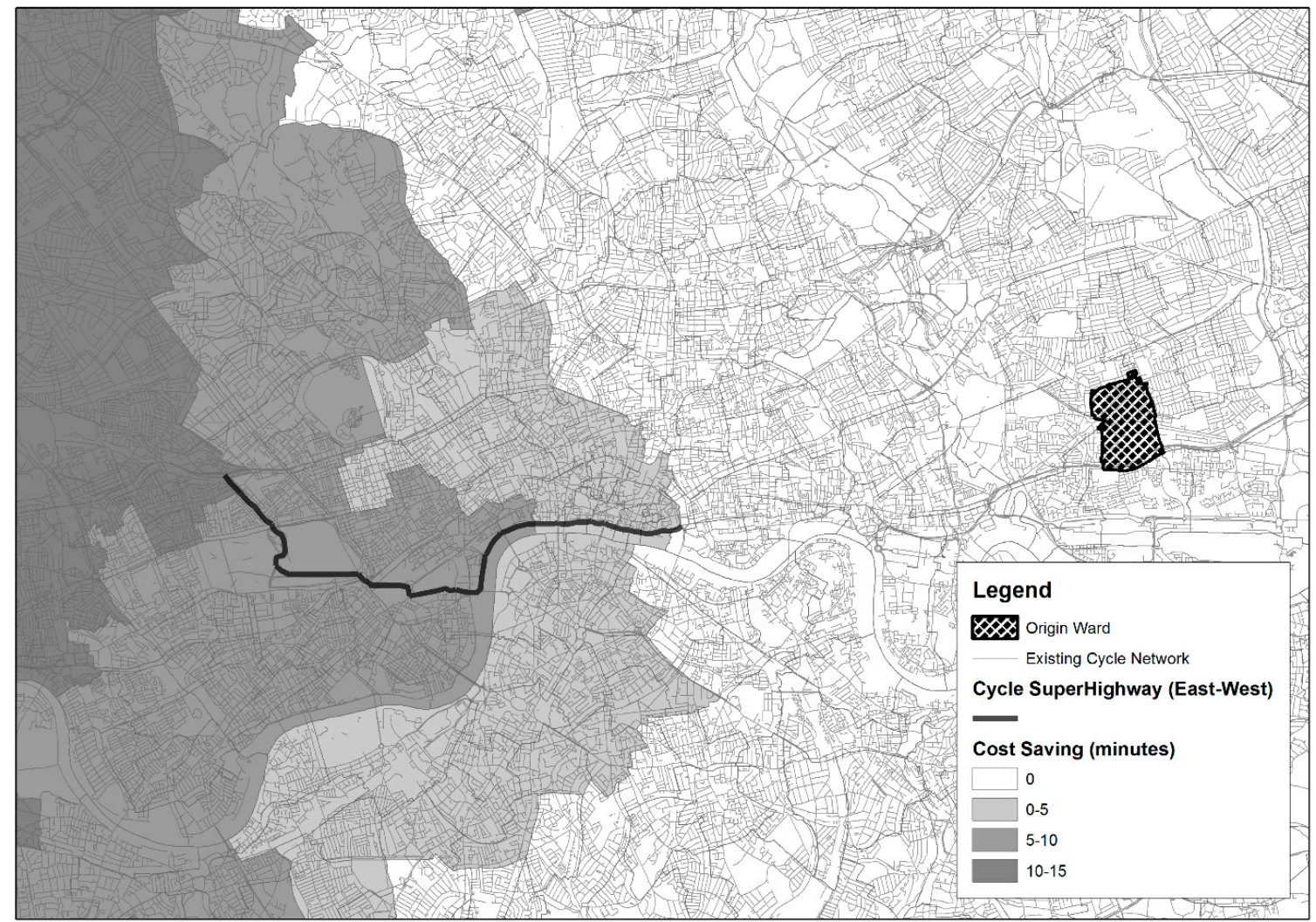

(C) OpenStreetMap contributors

Figure 7. Local improvements to cycle accessibility derived from implantation of the East-West Cycle Superhighway proposal.

\subsection{Accessibility to Employment within London}

Of the 30 million daily reported transport journeys in the 2012 London Travel Report [57], 40\% were work-related journeys. Accessibility to employment is therefore an important driver of demand on transport networks and a large contributor to greenhouse gas emissions from transport. Since the zones 
used in the generalized cost calculation are also zones where population and employment records are available, it is possible to examine the accessibility to employment within London - and thus assess the number of people for whom accessibility is improved. $44 \%$ of the journey stages documented in the 2012 London Travel Report were by public transport, with 33\% by car. Therefore, whilst patronage of public transport modes is significant in London, there is room for improvement. Providing lower travel costs between home and work locations by more sustainable transport modes could encourage fewer journeys by carbon-intensive modes, and this is a key driver in the London Plan [58].

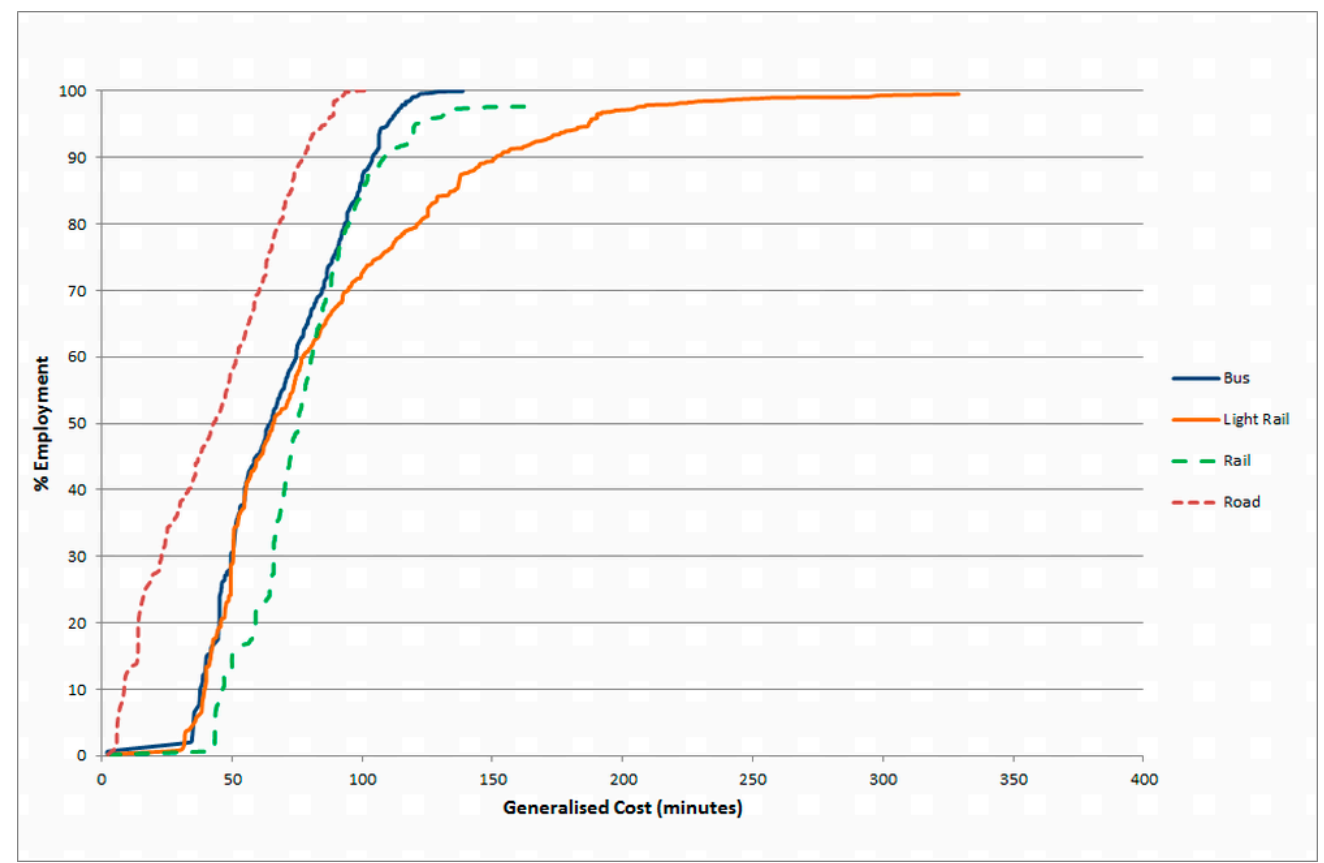

(a)

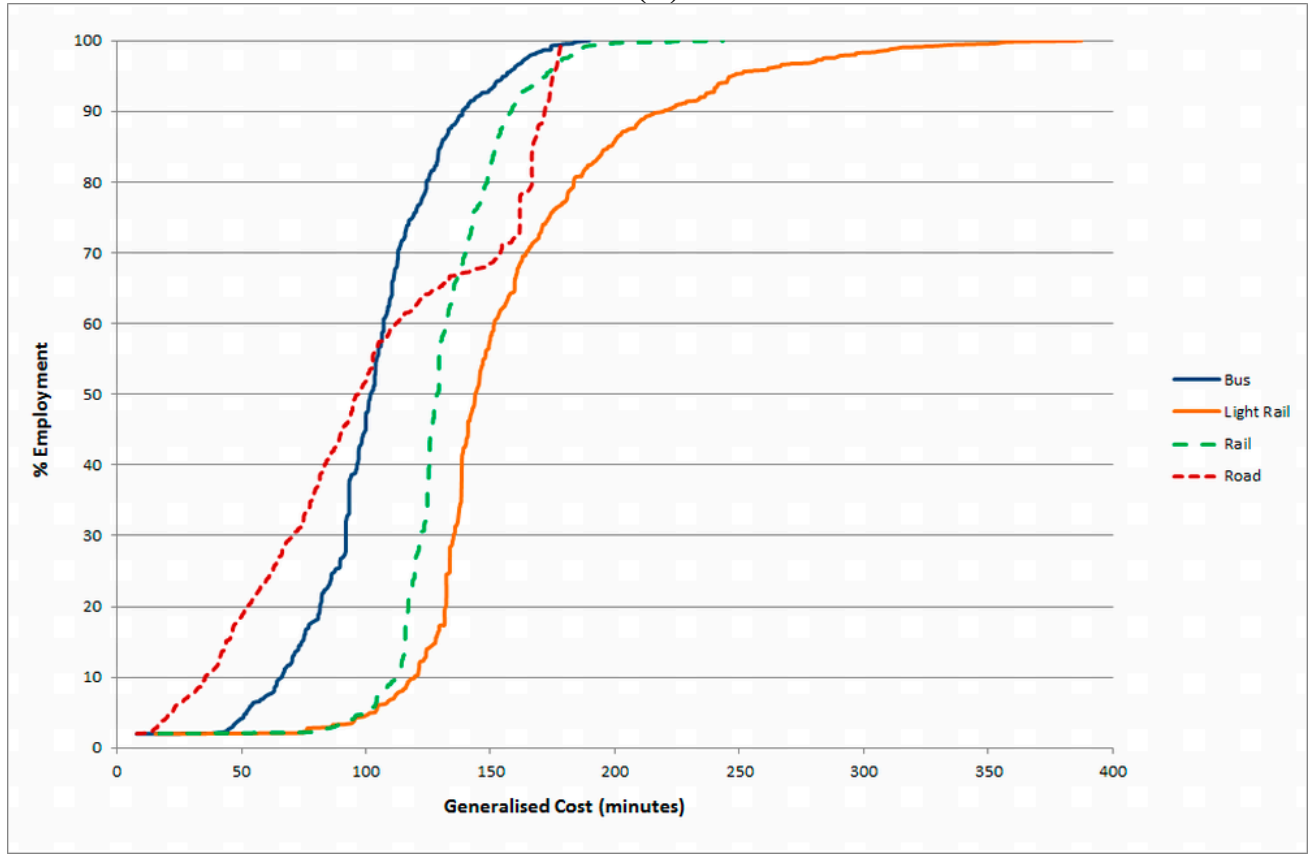

(b)

Figure 8. Employment accessibility functions for the (a) Aldersgate ward in Central London and (b) Heathrow Villages ward in West London. 
The 2008 Annual Business Inquiry data [59] provided total employment in each of the zones utilized in the study and used to construct functions of the proportion of London's employment $(\sim 3.5$ million jobs) that is accessible for a given generalized cost of travel from each of the 633 census wards. Figure 8 shows these employment accessibility functions for the Heathrow Villages ward (Figure 8a) and Aldersgate ward (Figure $8 \mathrm{~b}$ ) for the road, rail, light rail, and bus modes for current transport infrastructure. Travel by cycling does not feature in these accessibility functions as it was important to be able to examine accessibility to all employment in the study area. The average cycling trip length recorded in the UK National Travel Survey in 2012 [60] was 3.2 miles, suggesting that cycles are used mainly for short-distance trips. Since these curves examine accessibility to employment across the whole Greater London area, cycling costs were not included.

The shape of these functions is determined by the characteristics of the mode of travel (e.g., the access time, the frequency of service, the travel speeds) as well as the spatial location of the origin ward and the spatial distribution of employment. Wards, such as Aldersgate, situated nearest to centers of employment (e.g., the City of London or Canary Wharf) have more employment accessible at a lower generalized cost of travel than wards situated in the suburbs or in areas of low accessibility.

Aldersgate (Figure 8a) is located near a number of transport hubs within the Congestion Charge zone. The road mode gives access to a large proportion of jobs for comparatively low generalized cost (approximately 50\% of all of London's jobs within $40 \mathrm{~min}$ ) since this is an area of dense employment and the Congestion Charge is reduced by $90 \%$ for journeys originating within the zone. However, this does not include factors such as insufficient parking spaces which may preclude many journeys by this mode. The public transport modes all exhibit higher costs to access a similar level of employment but there is some variation across the modes. Heavy rail has a larger generalized cost than other modes to access employment initially (with a lag of $75 \mathrm{~min}$ ), highlighting the discentive required to walk to the nearest heavy railway station, but is a lower-cost option for accessing more distant employment than light rail (100\% of employment is reached in around $200 \mathrm{~min}$, whilst for light rail the cost is around $350 \mathrm{~min}$ ). The generalized cost to reach all employment by rail and light rail is higher than that by bus, showing the effect of low bus fares on the generalized cost of travel.

Figure $8 \mathrm{~b}$ shows comparable functions for journeys originating in the Heathrow Villages ward. It is immediately noticeable that the travel cost to access employment is higher for all destination wards, reflecting the spatial separation of this origin from the main employment centers in central London (100 min of travel cost to reach $50 \%$ of jobs by private transport in this instance). It is interesting to note the steepening of the function for the Road mode at $160 \mathrm{~min}$, which is due to the Congestion Charge reducing the accessibility of jobs by road within the charging zone. The initial lag in the Rail and Light Rail modes are due to the long access walks to those modes from this ward (since the ward centroid is $800 \mathrm{~m}$ from the nearest station, all of which are located within the airport). The spatial coverage of the Light Rail network, requires some long walks from the destination station to the workplace census ward, leading to a very long tail for the final $5 \%$ of jobs.

Both accessibility curves for the current day transport networks highlight a number of interesting patterns. Journeys by private car are, in the most part, the lowest cost means of accessing employment in Greater London (consistently up to 30 min lower in cost than other modes from Aldersgate). The Congestion Charge does, however, reduce the accessibility by this mode to the jobs in central London by adding $95 \mathrm{~min}$ to the cost of those journeys. Accessibility by more sustainable public transport modes 
is initially curtailed by the additional cost of accessing these modes initially (a lag of between 30 and $75 \mathrm{~min}$ ), but then over short distances in central London the light rail mode is competitive and over longer distances to the wider area the rail mode more attractive. The low cost of bus tickets in London ensures that, despite its relatively slow journey speeds, the overall generalized cost to access employment by this mode is low. Such comparisons suggest that in order to encourage uptake of lower-carbon forms of transport, either the costs of these transport option to access employment must be reduced (through investment or lower ticket prices) or the cost of private car travel must be increased (e.g., through ensuring the cost of car journeys reflects the true cost, for instance through carbon pricing). This paper highlights accessibility functions for only two wards, however such curves are produced for all wards by the generalized cost tool (i.e., 633 such curves for the GLA area).

Such employment accessibility functions can be used to examine benefits to accessibility from infrastructure improvement, as an alternative to examining individual generalized cost improvements as shown in Figures 5-7. Figure 9 shows the accessibility change from the Heathrow Villages ward as a result of different infrastructure scenarios which include investments from the Transport 2025 report (see Table 1). These curves show that accessibility as measured by generalized cost improves most notably in the bus mode (due to an increase in the frequency of bus services in the area). Other low-carbon modes, however, exhibit little overall change as a result of the proposed infrastructure improvements in the report. The largest difference in these scenarios is between road scenarios with and without the inclusion of the Congestion Charge. Since a large proportion of jobs (approximately 25\%) are located within this part of central London, the Congestion Charge can be seen as a large incentive for people to use lower-carbon forms of transport to access this employment.

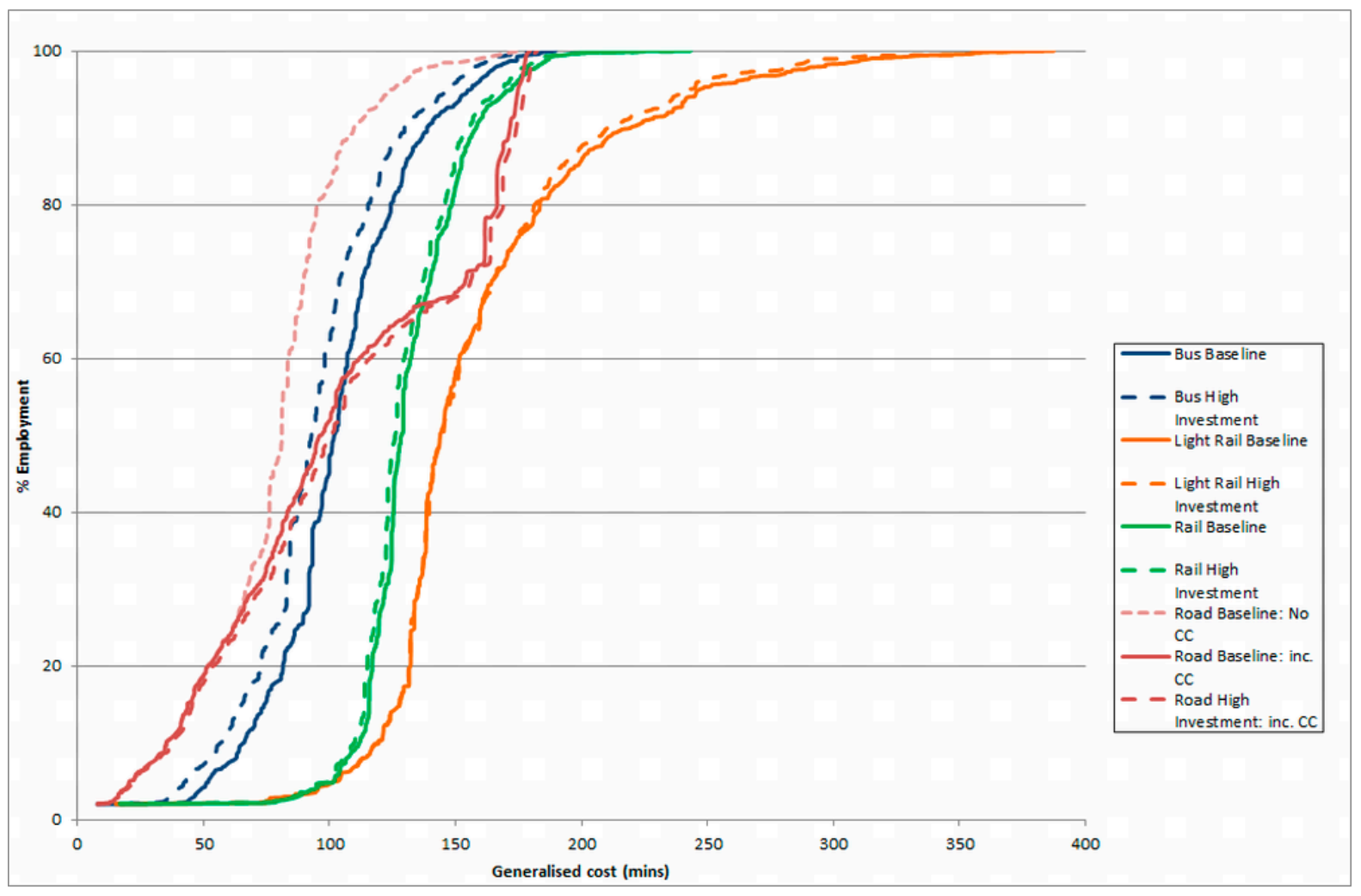

Figure 9. Employment accessibility functions for different transport scenarios, also showing sensitivity to road congestion charging (CC), for the Heathrow Villages ward. 


\subsection{Global Accessibility Improvements}

The impact and benefits of infrastructure change varies across each ward. To yield a global measure of employment accessibility, as opposed to the local measurement in Figure 9, we integrate the employment accessibility functions, weighted by residential population, for each ward. This measure of global accessibility, $A_{G}$, provides a non-spatial summary of the relationship between residential and employment locations and is calculated as:

$$
A_{G}=\sum_{i=1}^{N} \frac{P_{i}}{P_{T}} \sum_{j=1}^{N} E_{j} C_{i j}
$$

where $P_{i}$ and $E_{j}$ are the population and employment in wards $i$ and $j$, from 2008 data [59,61] and $P_{T}$ is the total population in London. This is therefore the aggregate generalized cost for accessing all employment in the region. Global accessibility for each transport mode, under different T2025 investment scenarios, is reported in Table 3. The Low and High investment scenarios lead to employment accessibility benefits across all public transport modes, with the greatest benefit for buses as a result of additional investment in bus frequencies reducing waiting times and thus generalized transport cost. In the High Investment road scenario it can be seen that the accessibility decreases rather than increases; this is because a national Road User Charging scheme increases overall costs of road use (charging a fixed price per $\mathrm{km}$ ). The higher investment strategy provides benefits to public transportation accessibility, contributing towards social inclusion [62] and decarbonization strategies. As with Figure 9, the Congestion Charge has a substantial impact on accessibility as a result of the number of jobs in this zone.

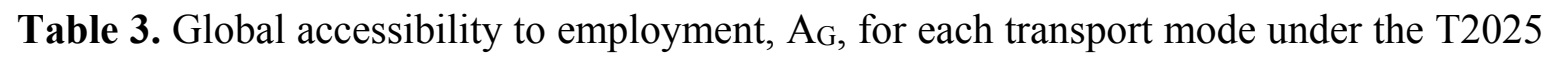
transport infrastructure investment scenarios (a lower value means lower cost to access employment and therefore better employment accessibility), and sensitivity of the road mode to congestion charging (CC).

\begin{tabular}{cccccc}
\hline & Bus & Light Rail & Rail & Road: With CC & Road: No CC \\
\hline Baseline & 9193 & 13868 & 9767 & 8548 & 6027 \\
Low investment & $9063(-1.4 \%)$ & $13,605(-1.9 \%)$ & $9575(-2.0 \%)$ & $8520(-0.3 \%)$ & $5997(-0.5 \%)$ \\
High investment & $8285(-9.9 \%)$ & $13,325(-3.9 \%)$ & $9490(-2.8 \%)$ & $8698(+1.7 \%)$ & $6176(-2.5 \%)$ \\
\hline
\end{tabular}

These global accessibility figures demonstrate significant differences (up to $60 \%$ in some cases) between the various modes and their ability to connect people with employment locations in London. It can be seen that on balance, global accessibility by the Road mode is lower than that of other public transport modes. This is in part due to some missing factors in the calculation of road generalized cost values (most significantly parking charges) but generally represents the lower cost of travel by car when taking into account all (monetary and temporal) factors. This demonstrates that encouraging the use of sustainable travel options must overcome the overall lower costs of private car travel in Greater London. However this global measure does not capture the local variability of accessibility across the area of interest, only providing a city-wide overview of the various modes. It is useful for comparison of various future investment scenarios and gives an understanding of the implications of policy decisions. Table 3 
shows accessibility to employment locations only, whilst access to other services (e.g., shops, parks, hospitals) would have different patterns and totals.

\section{Conclusions}

This paper has presented a GIS-based tool that has been developed to enable rapid characterisation of transport costs and accessibility over large spatial domains using readily available data. The results of this tool can be presented in a variety of ways, including as plots or graphs, and as spatial maps of generalized cost or accessibility. The key benefit of this approach is to enable rapid appraisal of the effects of new infrastructure developments on accessibility at a local to city-wide scale, and the comparison of accessibility patterns between competing modes. Te Brömmelstroet et al. [22] indicated that decision-makers find "visual map-based media to be a very useful tool for communicating accessibility" and that "planners prefer maps, while transport planners are more at ease when presented with quantitative outputs". The tool presented here has been designed to provide both such outputs using widely-available GIS software. Furthermore, this tool is provided as a free add-on for standard GIS and can use publicly-available data thereby addressing concerns of a significant proportion of local government organizations that lack the time, money, data, and computational skills to undertake accessibility analysis [22].

Application to Greater London shows that networks of different transport modes can be analyzed over large spatial scales, and reveals considerable spatial variability in transport costs and employment accessibility. Employment accessibility is shown to be a complex function of transport mode, network structure, location of jobs and journey origin. Globally, road-based modes provide the greatest accessibility, suggesting that investment may be needed in lower-carbon forms of transport in order to reduce the dominance of the private car in transport journeys (currently at $44 \%$ modal share). The Congestion Charge provides a substantial disincentive to commuting into central London by private transport and thus encouraging the use of other, less carbon-intensive modes of travel to access the jobs and services in this area. However, rail-based modes are still more beneficial on certain routes, highlighting the importance of considering spatial form in this type of analysis.

These accessibility functions provide decision-makers with depictions of the relative accessibility of key facilities (in this case employment locations) from a given location within an urban area. It is quickly demonstrated that certain modes of travel provide access to such locations for a lower generalized cost than other modes. It is possible, with the accessibility tool presented here, to examine the attractiveness of low-carbon modes of transport against less sustainable means of travel. Such functions also allow the testing of possible future infrastructure investment options, to quickly examine the impact of such investments on accessibility and to determine the effectiveness of options to increase the attractiveness of sustainable travel modes.

Rapid analysis of accessibility patterns helps explore a wide range of possible transport options to balance factors such as maintaining accessibility to employment, ensuring connectivity of residential areas, but also wider sustainability goals such as reduction in long-distance commuting, promoting low-carbon transport, and reducing travel emissions. Local accessibility changes (e.g., access to stations, effects of infrastructure improvements on short journeys) can be viewed in the context of city scale effects (e.g., global changes of accessibility) in order to ensure balanced portfolios of measures. 
Moreover, a rapid assessment tool allows inclusion of transport analysis in multi-sectoral analyses of urban sustainability studies, so that investment in transport infrastructure can be assessed alongside other investments in order to build a balanced portfolio of options which can assist in the development of sustainable urban areas (see Hall et al. [29]; Walsh et al. [30]; Dawson et al., [63]; and Echenique et al. [16] for studies of this kind).

In this study, we have considered only employment accessibility, but other measures such as access to green space, shops and other services could be readily included subject to data availability at the relevant spatial geography. We also considered each transport mode in isolation, and calculated access to each network independently of other possible travel modes. This enabled the relative accessibility of each transport mode to be compared directly, and for results of the analysis to be more readily interpreted and explained. However, we recognize that this may not always offer the least cost result for travel between two zones. A more realistic representation would allow for the computation of a walking, driving network path to a station — or indeed use of multiple modes of transport for the journey — which is the subject of ongoing work. Inevitably, broad scale models of this nature necessitate a number of assumptions that limit its potential for detailed transport infrastructure design and analysis. However, these limitations are justified in this case as the aim was to create an accessibility analysis tool that can be rapidly and widely-applied without the need for large, or bespoke, data collection exercises. Another advantage of such a simple approach is the ability to add more network layers, services or represent additional processes within the generalized cost calculation, if needed.

The value of such a tool, as opposed to a full macro transport model or microsimulation of traffic, is that many alternative scenarios of transport infrastructure and associated policies can be tested and compared quickly and easily. Constructing the modeling tools in a GIS framework facilitates parameterisation and preparation of these scenarios and enables immediate visual exploration and interpretation of the results. The tool has been made available for others to use (http://www.ncl.ac.uk/ceser/researchprogramme/software/). In addition, utilizing widely-available datasets, such as OpenStreetMap, demonstrates the transferability of the tool, and thus its future applicability to other cities in the world, particularly in the developing world where such transformations to sustainable transport are vital and where open and crowd-sourced data sources are becoming more prevalent.

\section{Acknowledgments}

This research was funded by the Engineering \& Physical Sciences Research Council ARCADIA: ARCADIA: Adaptation and Resilience in Cities: Analysis and Decision making using Integrated Assessment project (Grant No. EP/G061254/1), the European Community's Seventh Framework Programme under Grant Agreement No. 308497 Project RAMSES-Reconciling Adaptation, Mitigation, and Sustainable Development for Cities, and the Tyndall Center for Climate Change Research Cities programme. Richard Dawson is funded by an EPSRC fellowship (EP/H003630/1).

All maps contain Ordnance Survey data (C) Crown copyright and database right 2014. Light rail data is copyright Transport for London 2009. OpenStreetMap data is open data, licensed under the Open Data Commons Open Database License (ODbL). 


\section{Author Contributions}

All authors have contributed to the development of the research described in this article. Alistair Ford was the lead researcher in the development of the tools and production of the data, Richard Dawson analyzed the accessibility patterns and produced the resultant curves, whilst Stuart Barr oversaw the research project and reviewed the article during production. Philip James contributed to the review and preparation of the article.

\section{Conflicts of Interest}

The authors declare no conflict of interest.

\section{References}

1. Pooler, J.A. A family of relaxed spatial interaction models. Prof. Geogr. 1994, 46, 210-217.

2. Liu, S.; Zhu, X. An integrated GIS approach to accessibility analysis. Trans. GIS 2004, 8, 45-62.

3. Geurs, K.T.; van Wee, B. Accessibility evaluation of land-use and transport strategies: Review and research directions. J. Transp. Geogr. 2004, 12, 127-114.

4. Bristow, G.; Farrington, J.; Shaw, J.; Richardson, T. Developing an evaluation framework for crosscutting policy goals: The Accessibility Policy Assessment Tool. Environ. Plan. A 2009, 41, $48-62$.

5. Hull, A.; Silva, C.; Bertolini, L. Accessibility Instruments for Planning Practice; COST: Brussels, Belgium, 2012. Available online: http://www.accessibilityplanning.eu/wp-content/uploads/2012/10/ COST-Report-1-FINAL.pdf (accessed on 15 December 2013).

6. Van Wee, B. Evaluating the impact of land use on travel behaviour: The environment versus accessibility. J. Transp. Geogr. 2011, 19, 1530-1533.

7. Grengs, J. Job accessibility and the modal mismatch in Detroit. J. Transp. Geogr. 2010, 18, 42-54.

8. Foth, N.; Manaugh, K.M.; El-Geneidy, A. Towards equitable transit: Examining transit accessibility and social need in Toronto, Canada, 1996-2006. J. Transp. Geogr. 2013, 29, 1-10.

9. Rydin, Y. Spatial planning for sustainable urban development. In Governing for Sustainable Urban Development; Earthscan: London, UK, 2010; pp. 107-110.

10. Hansen, W. How accessibility shapes land use. J. Am. Inst. Plan. 1959, 25, 73-76.

11. Lowry, I.S. A Model of Metropolis RM-4035-RC; The Rand Corporation: Santa Monica, CA, USA, 1964.

12. Levinson, D.M. Accessibility and the journey to work. J. Transp. Geogr. 1998, 6, 11-21.

13. Forrester, J.W. Urban Dynamics; MIT Press: Cambridge, MA, USA, 1969.

14. Wegener, M. Applied models of urban land use, transport and environment: State of the art and future developments. In Network Infrastructure and the Urban Environment. Advances in Spatial Systems Modelling; Lundqvist, L., Mattsson, L.-G., Kim, T.J., Eds.; Springer Verlag: Berlin/Heidelberg, Germany, 1998; pp. 245-267.

15. Waddell, P. UrbanSim: Modeling urban development for land use, transportation and environmental planning. J. Am. Plan. Assoc. 2002, 68, 297-314. 
16. Echenique, M.H.; Hargreaves, A.J.; Mitchell, G.; Namdeo, A. Growing cities sustainably: Does urban form really matter? J. Am. Plan. Assoc. 2012, 78, 121-137.

17. Clarke, K.C. A decade of cellular urban modeling with SLEUTH: Unresolved issues and problems. In Planning Support Systems for Cities and Regions; Brail, R.K., Ed.; Lincoln Institute of Land Policy: Cambridge, MA, USA, 2008; pp. 47-60.

18. Batty, M. Building a Science of Cities; UCL Working Papers Series No. 170; University College London: London, UK, November 2012.

19. Hunt, J.D.; Kriger, D.S.; Miller, E.J. Current operational urban land-use-transport modelling frameworks: A review. Transp. Rev. 2005, 25, 329-376.

20. Cooper, S.; Wright, P.; Ball, R. Measuring the accessibility of opportunities and services in dense urban environments: Experiences from London. In Proceedings of the European Transport Conference 2009, Noordwijkerhout, The Netherlands, 5 October 2009.

21. Brown, M.; Wood, T. Accession-Accessibility analysis for local transport planning. In Proceedings of the European Transport Conference 2004, Strasbourg, France, 4 October 2004.

22. Te Brömmelstroet, M.; Silva, C.; Bertolini, L. COST Action-Assessing Usability of Accessibility Instruments; COST Office: Brussels, Belgium, 2014.

23. O'Sullivan, D.; Morrison, A.; Shearer, J. Using desktop GIS for the investigation of accessibility by public transport: An isochrone approach. Int. J. Geogr. Inf. Sci. 2000, 14, 85-104.

24. Lei, T.L.; Church, R.L. Mapping transit-based access: Integrating GIS, routes and schedules. Int. J. Geogr. Inf. Sci. 2010, 24, 283-304.

25. Benenson, I.; Martens, K.; Rofé, Y.; Kwartler, A. Public transport versus private car GIS-based estimation of accessibility applied to the Tel Aviv metropolitan area. Ann. Reg. Sci. 2010, 47, 499-515, doi:10.1007/s00168-010-0392-6.

26. Mavoa, S.; Witten, K.; McCreanor, T.; O’Sullivan, D. GIS based destination accessibility via public transit and walking in Auckland. J. Transp. Geogr. 2012, 20, 15-22.

27. Chen, S.; Claramunt, C.; Ray, C. A spatio-temporal modelling approach for the study of the connectivity and accessibility of the Guangzhou metropolitan network. J. Transp. Geogr. 2014, 36, $12-25$.

28. Curtis, C.; Scheurer, J. Planning for sustainable accessibility: Developing tools to aid discussion and decision making. Prog. Plan. 2010, 74, 53-106.

29. Hall, J.W.; Dawson, R.J.; Walsh, C.L.; Barker, T.; Barr, S.L.; Batty, M.; Bristow, A.L.; Burton, A.; Carney, S.; Dagoumas, A.; et al. Engineering Cities: How Can Cities Grow Whilst Reducing Emissions and Vulnerability?; The Tyndall Centre for Climate Change Research: Newcastle, UK, 2009.

30. Walsh, C.L.; Dawson, R.J.; Hall, J.W.; Barr, S.L.; Batty, M.; Bristow, A.L.; Carney, S.; Dagoumas, A.; Ford, A.; Tight, M.R.; et al. Assessment of climate change mitigation and adaptation in cities. Proc. ICE: Urban Des. Plan. 2011, 164, 75-84, doi:10.1680/udap.2011.164.2.75.

31. Wachs, M.; Kumagi, T.G. Physical accessibility as a social indicator. Soc.-Econ. Plan. Sci. 1973, 7, 437-456.

32. Allen, W.B.; Liu, D.; Singer, S. Accessibility measures of U.S. metropolitan areas. Transp. Res. B 1992, 27, 439-449. 
33. Handy, S.L.; Niemeier, D.A. Measuring accessibility: An exploration of issues and alternatives. Environ. Plan. A 1997, 29, 1175-1194.

34. Koenig, J.G. Indicators of urban accessibility: Theory and application. Transportation 1980, 9, 145-172.

35. Miller, H.J. Measuring space-time accessibility benefits within transportation networks: Basic theory and computational methods. Geogr. Anal. 1999, 31, 87-212.

36. Makri, M.C.; Folkesson, C. Accessibility Measures for Analyses of Land Use and Travelling with Geographical Information Systems; Department of Technology and Society, Lund Institute of Technology, Lund University: Lund, Sweden; University \& Department of Spatial Planning, University of Karlskrona/Ronneby: Ronneby, Sweden, 1999.

37. Hillman, R.; Pool, G. GIS-based innovations for modeling public transport accessibility. Traffic Eng. Control 1997, 38, 554-559.

38. De Ortuzar, J.D.; Willumsen, L.G. Modelling Transport; John Wiley: New York, NY, USA, 2011.

39. Grey, A. The generalized cost dilemma. Transportation 1978, 7, 261-280.

40. Bruzelius, N.A. Microeconomic theory and generalised cost. Transportation 1981, 10, 233-245.

41. WebTAG Transport Analysis Guidance. Available online: http://www.dft.gov.uk/webtag/ (accessed on 30 September 2009).

42. Mackie, P.J.; Wadman, M.; Fowkes, A.S.; Whelan, G.; Nellthorp, J.; Bates, J. Values of Travel Time Savings in the UK. Available online: http://www.dft.gov.uk/pgr/economics/rdg/ valueoftraveltimesavingsinth3130 (accessed on 16 May 2009).

43. Nichols, A.J. Standard Generalised Cost Parameters for Modelling Inter-Urban Traffic and Evaluating Inter-Urban Road Schemes, Note 255; Department of the Environment, Mathematical Advisory Unit: London, UK, 1975.

44. Hopkinson, P.; Wardman, M. Evaluating the demand for new cycle facilities. Transp. Policy 1996, 3, 241-249.

45. Noland, R.B.; Kunreuther, H. Short-run and long-run policies for increasing bicycle transportation for daily commuter trips. Transp. Policy 1995, 2, 67-79.

46. Rodriguez, D.A.; Joo, J. The relationship between non-motorized mode choice and the local physical environment. Transp. Res. Part D: Transp. Environ. 2004, 9, 151-173, doi:10.1016/j.trd.2003.11.001.

47. Dijkstra, E.W. A note on two problems in connexion with graphs. Numer. Math. 1959, 1, 269-271.

48. ESRI. Network Analyst Documentation. Available online: http://www.esri.com/software/arcgis/ extensions/networkanalyst/index.html (accessed on 16 May 2009).

49. Feldman, O.; Simmonds, D.; Zachariadis, V.; Mackett, R.; Bosredon, M.; Richmond, E.; Nicoll, J. SIMDELTA - A microsimulation approach to household location modelling. In Proceedings of the World Conference on Transport Research 2007, University of California, Berkeley, CA, USA, 24-28 June 2007.

50. National Highway Traffic Safety Administration and the Bureau of Transportation Statistics National Survey of Pedestrian and Bicyclist Attitudes and Behaviors. Available online: http://www.nhtsa.gov/DOT/NHTSA/Traffic\%20Injury\%20Control/Articles/Associated\%20Files/ 810971.pdf (accessed on 2 January 2014). 
51. TFL. Transport 2025-Transport Vision for a Growing World City; TfL Group Transport and Planning Policy: London, UK, 2006.

52. TFL. London Travel Report; Transport for London: London, UK, 2006; p. 40.

53. TFL. London Congestion Charge Information; Transport for London: London, UK. Available online: http://www.tfl.gov.uk/roadusers/congestioncharging/6709.aspx (accessed on 12 December 2013).

54. Cyclestreets Journey Planner, How It Works, Cyclestreets.net. Available online: http://www.cyclestreets.net/journey/help/howitworks/ (accessed on 25 November 2014).

55. Crossrail Route Maps. Available online: http://www.crossrail.co.uk/route/maps/route-map (accessed on 29 October 2014).

56. TFL. Citizen Hub Consultation on East-West Cycle Superhighway. Available online: https://consultations.tfl.gov.uk/cycling/eastwest (accessed on 22 October 2014).

57. Travel in London, Report 6; p. 124. Available online: https://www.tfl.gov.uk/cdn/static/cms/ documents/travel-in-london-report-6.pdf (accessed on 20 October 2014).

58. GLA. The London Plan: Spatial Development Strategy for Greater London; Greater London Authority: London, UK, 2011.

59. ONS Nomis Annual Business Inquiry Dataset. Available online: http://www.nomisweb.co.uk (accessed on 14 January 2010).

60. DfT. National Travel Survey 2012: Statistical Release; UK Department for Transport: London, UK. Available online: https:/www.gov.uk/government/uploads/system/uploads/attachment_data/file/ 243957/nts2012-01.pdf (accessed on 10 October 2014).

61. ONS National Projections: UK Population to Exceed $65 \mathrm{~m}$ by 2018, Office for National Statistics. Available online: http://www.ons.gov.uk/ons/dcp171780_229187.pdf (accessed on 5 December 2013).

62. Farrington, J.; Farrington, C. Rural accessibility, social inclusion and social justice: Towards conceptualisation. J. Transp. Geogr. 2005, 13, 1-12.

63. Dawson, R.J.; Ball, T.; Werritty, J.; Werritty, A.; Hall, J.W.; Roche, N. Assessing the effectiveness of non-structural flood management measures in the Thames Estuary under conditions of socio-economic and environmental change. Glob. Environ. Chang. 2011, 21, 628-646, doi:10.1016/j.gloenvcha.2011.01.013.

(C) 2015 by the authors; licensee MDPI, Basel, Switzerland. This article is an open access article distributed under the terms and conditions of the Creative Commons Attribution license (http://creativecommons.org/licenses/by/4.0/). 